\title{
Emerging concepts on the anti-inflammatory actions of carbon monoxide-releasing molecules (CO-RMs)
}

\author{
Roberto Motterlini", Benjamin Haas and Roberta Foresti
}

\begin{abstract}
Carbon monoxide-releasing molecules (CO-RMs) are a class of organometallo compounds capable of delivering controlled quantities of $\mathrm{CO}$ gas to cells and tissues thus exerting a broad spectrum of pharmacological effects. CO-RMs containing transition metal carbonyls were initially implemented to mimic the function of heme oxygenase-1 (HMOX1), a stress inducible defensive protein that degrades heme to $\mathrm{CO}$ and biliverdin leading to anti-oxidant and anti-inflammatory actions. Ten years after their discovery, the research on the chemistry and biological activities of CO-RMs has greatly intensified indicating that their potential use as CO delivering agents for the treatment of several pathological conditions is feasible. Although CO-RMs are a class of compounds that structurally diverge from traditional organic-like pharmaceuticals, their behaviour in the biological environments is progressively being elucidated revealing interesting features of metal-carbonyl chemistry towards cellular targets. Specifically, the presence of carbonyl groups bound to transition metals such as ruthenium, iron or manganese appears to make CO-RMs unique in their ability to transfer CO intracellularly and amplify the mechanisms of signal transduction mediated by CO. In addition to their well-established vasodilatory activities and protective effects against organ ischemic damage, CO-RMs are emerging for their striking anti-inflammatory properties which may be the result of the multiple activities of metal carbonyls in the control of redox signaling, oxidative stress and cellular respiration. Here, we review evidence on the pharmacological effects of CO-RMs in models of acute and chronic inflammation elaborating on some emerging concepts that may help to explain the chemical reactivity and mechanism(s) of action of this distinctive class of compounds in biological systems.
\end{abstract}

Keywords: Inflammation, Carbon monoxide-releasing molecules (CO-RMs), Oxidative stress, Inflammatory mediators, Bactericidal activities

\section{Introduction}

The heme oxygenase enzymes (HMOX1 and HMOX2) generate, among other interesting molecules, the gas carbon monoxide (CO) [1]. The quantity of the gas produced over time depends on the tissue examined, as HO-2 is constitutively expressed in the endothelium, testes and brain while HMOX1 is highly inducible in all tissues by many kinds of stressful stimuli [2]. In addition, the availability of the substrate heme, which is cleaved by heme oxygenases in the $\alpha$ position to release $\mathrm{CO}$, will strictly determine how much $\mathrm{CO}$ can be produced in the cell. However, it is expected that $\mathrm{CO}$ levels will increase

* Correspondence: roberto.motterlini@inserm.fr; roberta.foresti@inserm.fr INSERM U955, Equipe 3, Faculty of Medicine, University Paris-Est Creteil, Creteil, France upon up-regulation of HMOX1 and this has been demonstrated in some studies that directly measured CO production ex-vivo [3,4]. Research conducted in the past years has progressively elucidated the role of HMOX1 in mammalian systems. The protein was recognized early on as an important component of the stress response $[5,6]$ but it was only when detailed exploration of the function of its products was performed that an indispensable action for HMOX1 as an anti-oxidant and anti-inflammatory system emerged $[7,8]$. CO appears to contribute most significantly to these anti-inflammatory activities by regulating a variety of transcription factors, inflammatory proteins and pathways [9-11]. This role is consistent across many inflammatory conditions, 
although the specific pathways affected might differ from one disease to another.

Exposure of cells, tissues and animals to sub-toxic amounts of $\mathrm{CO}$ gas has been used successfully to reproduce the anti-inflammatory properties of HMOX1 and has helped to unravel many of the mechanisms underlying this effect $[10,11]$. The use of $\mathrm{CO}$ gas as a therapeutic agent is also underscored by clinical trials currently ongoing in patients who will receive $\mathrm{CO}$ by inhalation for the treatment of pulmonary arterial hypertension, post-operative ileus and idiopathic pulmonary fibrosis (see www.clinicaltrials.gov). In parallel and as an alternative to this experimental approach, we have focused our strategy on utilizing chemicals that could bind and carry $\mathrm{CO}$ stably but deliver the gas when used in biological systems. We have identified and termed these compounds CO-releasing molecules (CO-RMs) [12-14] and have extensively studied their biochemical, biological and pharmacological effects in many in vitro and in vivo models of disease [9,15-17]. The chemical structure of the best characterized CO-RMs (CORM-2, CORM-3, CORM-A1 and CORM-376) is represented in Figure 1 (see also chemical formula in List of Abbreviations). Thanks to strong collaborations with chemists, we have generated CO-RMs with improved water solubility, diverse chemical structures, various rates of $\mathrm{CO}$ release and stability $[9,15,58-60]$. The results have been encouraging as the concentrations and doses of CORMs used in all studies were such that the final $\mathrm{CO}$ exposure was below the threshold believed to cause toxicity. In addition, as shown in Table 1, the data obtained so far support promising pharmacological actions of CO-RMs that could be useful to counteract inflammatory conditions. Metal carbonyl complexes, containing ruthenium, iron or manganese as metal center, and boranocarbonates are the two major classes of CO-RMs in our portfolio $[15,16,59,61]$. Our own investigations and studies with collaborators revealed that metal carbonyls are better anti-inflammatory agents than boranocarbonates but the reasons for this difference are unknown at present. The chemistry and pharmacological pro perties of these compounds is becoming a topic of great interest since in the last 2-3 years other research groups have synthesized a variety of different new CO-RMs. Recently ruthenium imidazole oxime car bonyls [62], photoactive and nanoCO-RMs [63,64], enzyme-triggered CO-RMs [65], CO-RMs encapsulated in micelles [66] and rhenium-based CO-RMs [67] have been developed. However, for most of these new molecules a detailed picture of their behaviour in cells, tissues and in vivo models of disease is not yet available, and will be required to evaluate their full pharmacological potential. In this context it is important to emphasize that, once $\mathrm{CO}$ is liberated, the potential toxicity of the residual molecule containing the transition metal needs to be carefully evaluated. To date a systematic in vivo toxicological profile of CO-RMs has not yet been performed but this will be required once a lead compound will be identified for a given pathological indication.

In this article we will review the role of CO-RMs in protection against inflammatory conditions, focusing primarily on their effect on oxidative stress and nitric oxide (NO) production, two of the main initiators of the inflammatory cascade. The biochemical and physiological assays used to determine CO liberation or transfer of $\mathrm{CO}$ to cellular targets and their interesting anti-bacterial actions will also be discussed.<smiles></smiles>

CORM-2

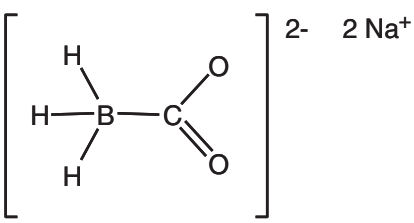

CORM-A1<smiles>O=C[C@@]1(O)NCC(=O)O1</smiles>

CORM-3

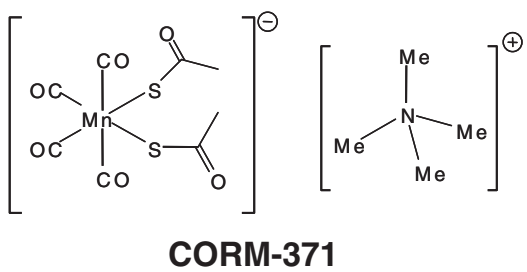

Figure 1 Chemical structure of the best characterized CO-RMs which have been shown to exert anti-inflammatory and anti-bacterial activities in vitro and in vivo (see also Table 1 for more details). 
Table 1 Effect of CO-RMs on in vitro and in vivo inflammatory disease models

\begin{tabular}{|c|c|c|c|}
\hline \multirow[t]{2}{*}{ Type of CO-RM } & Inflammatory disease models & Effect on inflammatory markers/ & \multirow[t]{2}{*}{ Reference } \\
\hline & in vitro and in vivo & Overall outcome & \\
\hline \multirow[t]{2}{*}{ CORM-3 } & \multirow[t]{2}{*}{ Vascular thrombosis in rats } & $\downarrow$ fibrinogen and fibrin & \multirow[t]{2}{*}{ [18] } \\
\hline & & $\uparrow$ pro-thrombin & \\
\hline \multirow[t]{2}{*}{ CORM-3 } & \multirow[t]{2}{*}{ Hemorrhagic stroke induced by collagenase in rats } & $\downarrow$ TNF-a production & \multirow[t]{2}{*}{ [19] } \\
\hline & & $\downarrow$ brain injury & \\
\hline \multirow[t]{3}{*}{ CORM-2 } & \multirow{3}{*}{$\begin{array}{l}\text { Polymicrobial sepsis induced by cecal ligation and perforation (CLP) in } \\
\text { mice }\end{array}$} & $\uparrow$ protein $C$ system & \multirow[t]{3}{*}{ [20] } \\
\hline & & $\downarrow$ plasma thrombomodulin & \\
\hline & & $\begin{array}{l}\downarrow \text { number of thrombi in liver, kidney and } \\
\text { lung }\end{array}$ & \\
\hline \multirow[t]{4}{*}{ CORM-3 } & \multirow[t]{4}{*}{ Postmenopausal rheumatoid arthritis osteoporosis in mice } & $\begin{array}{l}\downarrow \text { cellular infiltration and cartilage } \\
\text { degradation }\end{array}$ & \multirow[t]{4}{*}{ [21] } \\
\hline & & $\downarrow$ TNF-a production & \\
\hline & & $\begin{array}{l}\downarrow \text { Serum levels of IL-6, alkaline } \\
\text { phosphatase and }\end{array}$ & \\
\hline & & MMP-3 & \\
\hline \multirow[t]{2}{*}{ CORM-2 } & \multirow{2}{*}{$\begin{array}{l}\text { Coagulation and fibrinolitic markers in human umbilical vein endothelial } \\
\text { cells (HUVEC) }\end{array}$} & $\downarrow$ tissue factor & \multirow[t]{2}{*}{ [22] } \\
\hline & & $\begin{array}{l}\downarrow \text { plasminogen activator inhibitor type } 1 \\
\text { (PAl-1) }\end{array}$ & \\
\hline CORM-2 & \multirow[t]{4}{*}{ Neuropatic pain and microglia activation in mice induced by nerve injury } & $\downarrow$ mechanical allodynia & \multirow[t]{4}{*}{ [23] } \\
\hline \multirow[t]{3}{*}{ CORM-3 } & & $\downarrow$ thermal hyperalgesia & \\
\hline & & $\downarrow \mathrm{nNOS}$ and iNOS expression & \\
\hline & & $\downarrow$ microglial marker (CD11b/c) & \\
\hline CORM-3 & \multirow[t]{4}{*}{ Vascular inflammation in human umbilical vein endothelial cells (HUVEC) } & $\downarrow$ VCAM-1 and ECAM expression & \multirow[t]{4}{*}[24-26]{} \\
\hline \multirow[t]{3}{*}{ CORM-2 } & & $\downarrow N F-k \beta$ and $p 38-M A P K$ expression & \\
\hline & & $\downarrow$ mitochondrial respiration & \\
\hline & & $\downarrow N F-k \beta$ and iNOS expression & \\
\hline CORM-2 & \multirow[t]{2}{*}{ Ischemia-reperfusion injury after kidney transplantation in rats } & $\uparrow$ survival rate & \multirow[t]{2}{*}{ [27] } \\
\hline CORM-3 & & $\begin{array}{l}\downarrow \text { acute tubular necrosis and } \\
\text { hemorrhage }\end{array}$ & \\
\hline \multirow[t]{3}{*}{ CORM-2 } & \multirow[t]{3}{*}{ Colitis induced by dextran sodium sulfate in mice } & $\downarrow$ disease activity index & [28] \\
\hline & & $\downarrow$ myeloperoxidase (MPO) activity & \\
\hline & & $\downarrow$ TNF-a production & \\
\hline CORM-2 & Endoplasmic reticulum (ER) stress induced by thapsigargin in human & $\downarrow$ C-reactive protein (CRP) & [29] \\
\hline CORM-3 & & $\downarrow$ serum amyloid P component (SAP) & \\
\hline CORM-2 & Cutaneous wound healing in rats & $\begin{array}{l}\uparrow \text { cell proliferation and wound } \\
\text { contraction }\end{array}$ & [30] \\
\hline & & $\uparrow$ collagen synthesis & \\
\hline & & $\begin{array}{l}\downarrow \text { TNF-a production and ICAM-1 } \\
\text { expression }\end{array}$ & \\
\hline & & $\uparrow I \mathrm{IL}-10$ production & \\
\hline CORM-2 & Acute hepatic ischemia-reperfusion injury in rats & $\uparrow$ anti-apoptotic protein Bcl2 & [31] \\
\hline & & $\downarrow$ markers of hepatic damage (AST/ALT) & \\
\hline & & $\downarrow$ serum levels of TNF- $a$ and IL- 6 & \\
\hline & & $\downarrow$ caspase activity and NF-k $\beta$ expression & \\
\hline CORM-2 & Acute pancreatitis in rats & $\downarrow$ serum levels of TNF- $\alpha$ and IL-1 $\beta$ & {$[32]$} \\
\hline & & $\downarrow N F-k \beta$ expression and MPO activity & \\
\hline & & $\uparrow \mid \mathrm{IL}-10$ production & \\
\hline
\end{tabular}




\section{Table 1 Effect of CO-RMs on in vitro and in vivo inflammatory disease models (Continued)}

\begin{tabular}{|c|c|c|c|}
\hline \multirow[t]{4}{*}{ CORM-3 } & \multirow[t]{4}{*}{ Rheumatoid arthritis induced by KBxN serum transfer in mice } & $\begin{array}{l}\uparrow \text { serum osteocalcin and } \mathrm{HO}-1 \\
\text { expression }\end{array}$ & \multirow[t]{4}{*}{ [33] } \\
\hline & & $\downarrow M M P-9, M M P-13$ and IL-1 $\beta$ expression & \\
\hline & & $\downarrow$ high mobility group box 1 (HMGB1) & \\
\hline & & $\begin{array}{l}\downarrow \text { Receptor activator of nuclear factor } \mathrm{KB} \\
\text { ligand (RANKL) }\end{array}$ & \\
\hline \multirow[t]{3}{*}{ CORM-2 } & \multirow[t]{3}{*}{ Ischemia-reperfusion induced inflammation of small intestine in mice } & $\downarrow$ TNF-a and ICAM expression & \multirow[t]{3}{*}{ [34] } \\
\hline & & $\downarrow$ leukocytes rolling and adhesion & \\
\hline & & $\downarrow N F-k \beta$ expression and MPO activity & \\
\hline \multirow[t]{4}{*}{ CORM-2 } & \multirow{4}{*}{$\begin{array}{l}\text { Inflammatory response induced by lipopolysaccharide in RAW } 264.7 \\
\text { macrophages and BV-2 microglia }\end{array}$} & $\downarrow$ iNOS mRNA and protein expression & \multirow[t]{4}{*}{ [35] } \\
\hline & & $\begin{array}{l}\uparrow \mathrm{COX}-2 \text { expression and NF-k } \beta \\
\text { expression }\end{array}$ & \\
\hline & & $\uparrow$ PGE2 levels & \\
\hline & & $\uparrow$ phosphorylation of Akt and MAPKs & \\
\hline \multirow[t]{5}{*}{ CORM-2 } & \multirow[t]{5}{*}{ Sepsis induced by cecal ligation and puncture (CLP) in mice } & $\begin{array}{l}\downarrow \text { neutrophil infiltration in broncoalveolar } \\
\text { lavage and liver }\end{array}$ & \multirow[t]{5}{*}[36-39]{} \\
\hline & & $\downarrow$ MPO activity in lung and NF- $k \beta$ in liver & \\
\hline & & $\begin{array}{l}\downarrow \text { serum TNF-a and high mobility group } \\
\text { box } 1 \text { (HMGB1) }\end{array}$ & \\
\hline & & $\downarrow$ nitrite/nitrate plasma levels & \\
\hline & & $\begin{array}{l}\uparrow \text { cardiac PGC-1a and mitochondrial } \\
\text { biogenesis }\end{array}$ & \\
\hline \multirow[t]{2}{*}{ CORM-A1 } & \multirow{2}{*}{$\begin{array}{l}\text { Inflammatory response induced by TNF- } a \text { in brain vascular endothelial } \\
\text { cells }\end{array}$} & $\downarrow$ NADPH oxidase activity & \multirow[t]{2}{*}{ [40] } \\
\hline & & $\downarrow$ apoptosis & \\
\hline CORM-3 & \multirow[t]{4}{*}{ Post-operative ileus in mice } & $\uparrow$ intestinal contractility and transit & \multirow[t]{4}{*}{ [41] } \\
\hline \multirow[t]{3}{*}{ CORM-A1 } & & $\uparrow \mid \mathrm{IL}-10$ and $\mathrm{HMOX} 1$ expression & \\
\hline & & $\downarrow \mathbb{L L}-6$ and iNOS expression & \\
\hline & & $\downarrow$ leukocyte infiltration & \\
\hline \multirow[t]{3}{*}{ CORM-2 } & \multirow{3}{*}{$\begin{array}{l}\text { Inflammatory response in liver and small intestine of thermally injured } \\
\text { mice }\end{array}$} & $\downarrow$ TNF- $\alpha, I L-1 \beta$ and iNOS expression & \multirow[t]{3}{*}[42,43]{} \\
\hline & & $\downarrow$ leukocyte infiltration & \\
\hline & & $\downarrow N F-k \beta$ and ICAM-1 expression & \\
\hline CORM-3 & \multirow[t]{6}{*}{ Bacterial activity in vitro and bacterial infection in vivo } & $\begin{array}{l}\downarrow \text { E. Coli and } P \text {. Aeuruginosa growth } \\
\text { in vitro }\end{array}$ & \multirow[t]{6}{*}[17,44-48]{} \\
\hline CORM-2 & & $\begin{array}{l}\uparrow \text { bacteriostatic and bactericidal effects } \\
\text { in vivo }\end{array}$ & \\
\hline CORM-A1 & & $\uparrow$ increased phagocytosis in vivo & \\
\hline CORM-371 & & $\downarrow$ respiration in bacteria & \\
\hline ALF-021 & & $\uparrow$ survival after bacterial infection in vivo & \\
\hline ALF-062 & & $\downarrow$ high mobility group box 1 (HMGB1) & \\
\hline \multirow[t]{4}{*}{ CORM-3 } & \multirow[t]{4}{*}{ Collagen-induced arthritis in mice } & $\downarrow$ prostaglandin E2 (PGE2) & \multirow[t]{4}{*}[49]{} \\
\hline & & $\begin{array}{l}\downarrow \text { pro-inflammatory interleukins (IL-1 } \beta, \\
\text { IL-2, IL-6) }\end{array}$ & \\
\hline & & $\uparrow$ anti-inflammatory interleukins (IL-10) & \\
\hline & & $\begin{array}{l}\downarrow \text { expression of cyclooxygenase-2 (COX- } \\
\text { 2) }\end{array}$ & \\
\hline \multirow[t]{3}{*}{ CORM-3 } & \multirow{3}{*}{$\begin{array}{l}\text { Vascular inflammation in human neutrophils and rat primary endothelial } \\
(\mathrm{EC}) \text { and mast (MC) cells }\end{array}$} & $\downarrow$ oxidative burst in human PMNs & {$[50]$} \\
\hline & & $\downarrow$ expression of CD54 in rat ECs & \\
\hline & & $\downarrow$ histamine in MCs & \\
\hline
\end{tabular}


Table 1 Effect of CO-RMs on in vitro and in vivo inflammatory disease models (Continued)

\begin{tabular}{|c|c|c|c|}
\hline \multirow[t]{5}{*}{ CORM-2 } & \multirow{5}{*}{$\begin{array}{l}\text { Inflammatory response induced by pro-inflammatory cytokines in Caco-2 } \\
\text { cells and human chondrocytes }\end{array}$} & $\downarrow$ prostaglandin E2 (PGE2) and nitrite & \multirow[t]{5}{*}[51-53]{} \\
\hline & & $\downarrow$ ROS production & \\
\hline & & $\downarrow$ COX-2 and iNOS protein expression & \\
\hline & & $\downarrow N F-k \beta$ expression & \\
\hline & & $\downarrow$ metalloproteinase-7 (MMP-7) & \\
\hline CORM-3 & \multirow{3}{*}{$\begin{array}{l}\text { Leukocyte-endothelial interaction in vitro and in a models of acute } \\
\text { pancreatitis and paw edema in mice }\end{array}$} & $\downarrow$ PMNs leukocytes in peritoneal cavity & \multirow[t]{3}{*}[54]{} \\
\hline \multirow[t]{2}{*}{ CORM-A1 } & & $\downarrow$ PMNs rolling on endothelial cells & \\
\hline & & $\downarrow$ paw edema and swelling & \\
\hline \multirow[t]{2}{*}{ CORM-3 } & \multirow{2}{*}{$\begin{array}{l}\text { Inflammatory response induced by LPS/INFY and hypoxia in BV2 microglia } \\
\text { cells }\end{array}$} & $\downarrow$ nitrite and TNF-a production & \multirow[t]{2}{*}[55,56]{} \\
\hline & & $\downarrow$ hypoxia-reoxygenation damage & \\
\hline CORM-2 & \multirow{2}{*}{$\begin{array}{l}\text { Inflammatory response induced by lipopolysaccharide in RAW } 264.7 \\
\text { macrophages }\end{array}$} & \multirow[t]{2}{*}{$\downarrow$ nitrite and TNF-a production } & \multirow[t]{2}{*}[57]{} \\
\hline CORM-3 & & & \\
\hline
\end{tabular}

\section{Anti-inflammatory actions of CO-RMs}

Inflammation and host defense are necessary and intrinsic processes that serve to protect organisms from a series of pathological challenges. The mechanisms that accompany the inflammatory response involve multiple cell types, signalling pathways and transcriptional factors and inflammation appears to be relevant for the vast majority of chronic diseases as well as in acute conditions [68]. That HMOX1 is a key player in mitigating inflammation was first reported in a model of carrageenin-induced pleurisy in rats, in which the evolution of inflammation was accompanied by a dramatic increase in HMOX1 levels and inhibition of heme oxygenase activity enhanced inflammatory markers [69].
In addition, HMOX1 deficiency in human subjects exhibited high levels of vascular inflammation and oxidative stress [70], a finding which is highly reproducible in mice lacking this stress protein [71]. Although bilirubin and biliverdin, endowed with potent antioxidant properties, may be important contributors that fight inflammation [72,73], CO gas applied exogenously is often found to recapitulate many of the anti-inflammatory actions elicited by HMOX1 [74]. Our work on the discovery and characterization of CO-RMs was carried out while novel findings by Otterbein et al. described the powerful effect of $\mathrm{CO}$ gas in inhibiting the production of pro-inflammatory cytokines (TNF- $\alpha$, IL-1 $\beta$ ) stimulated by lypopolysaccharide (LPS) in vitro and in vivo, showing

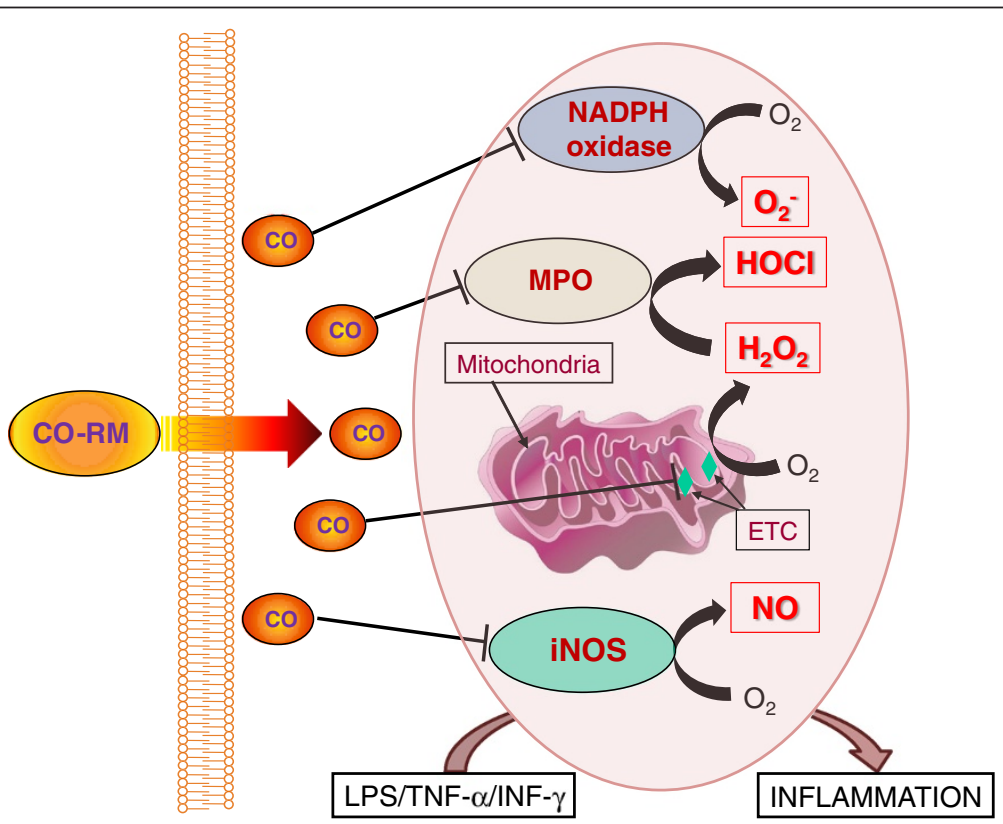

Figure 2 Graphical representation summarizing the mechanism(s) potentially involved in the anti-inflammatory activities of CO-RMs (see text for details). 
at the same time that $\mathrm{CO}$ induced the expression of the anti-inflammatory cytokine IL-10 and that mitogen activated protein kinases (MAPKs) mediated this phenomenon [8]. This and other exciting work stimulated our efforts in the development of CO-RMs and in trying to understand their efficacy in disease models. From an anti-inflammatory perspective, CO-RMs can affect multiple cell types and pathways that coordinate the inflammatory cascade (see Table 1 for a summary of the anti-inflammatory activities of CO-RMs in various in vitro and in vivo models). For example, Urquhart et al found that CORM-3 strongly reduced neutrophil extravasation in the peritoneum of zymosan-treated mice and inhibited expression of adhesion molecules in human polymorphonuclear neutrophils (PMNs) [54]. Still focusing on PMNs, Sun and co-workers showed that CORM-2 attenuated the leukocyte sequestration, $\mathrm{Nfk} \beta$ activation and endothelial protein expression of ICAM-1 in the lung of thermally injured mice [75]. The multiple effects of CO-RMs were particularly well dissected in a study by Masini et al. where human PMNs primed to elicit an inflammatory response were coincubated with rat endothelial cells or perivascular mast cells [50]. Here the authors clearly showed that CORM-3 down-regulated the oxidative burst in PMNs, the over-expression of adhesion molecules in PMNs and endothelial cells and the release of histamine and upregulation of an activation marker by mast cells. These results indicate how CORM-3 modulates acute inflammation by reducing the activation of PMNs, the first responders in host defense, but also by inhibiting expression of molecules and inflammatory factors that perpetuate the inflammatory process. In RAW macrophages and BV-2 microglia we have also shown concentration-dependent decreases in nitrite and TNF- $\alpha$ production by CORM-2 and CORM-3 following challenge with LPS [55-57].

The in vivo anti-inflammatory action of CO-RMs has also been consistently described. The group of Alcaraz has performed a series of detailed investigations in arthritis models $[21,33,49]$ and demonstrated that daily treatment with CORM-2 or CORM-3 can effectively suppress the clinical and histopathological manifestations of disease. Levels of PGE-2 and many other inflammatory mediators were reduced in the joint and this resulted in a better preservation of cartilage tissue and bone structures [33]. However, modulation of inflammatory molecules levels surely is not the only mechanism contributing to the CO-RMs mediated protection against inflammation and the data by Lancel and colleagues point to mitochondria as very important cellular organelles that are affected by CO-RMs. In a model of sepsis induced by cecal ligation, CORM-3 administration conserved cardiac mitochondrial function by preventing sepsis-mediated damage to mitochondria thus preserving membrane potential and respiration and inducing mitochondrial biogenesis [36]. In the heart of mice fed a high fat diet to mimic a metabolic syndrome-like disorder CORM-3 also stimulated mitochondrial biogenesis [76]. The mode of action and efficacy of CO-RMs may also depend on the timing of administration in relation to the pathology studied, as exemplified recently by our investigation in a model of hemorrhagic stroke in rats [19]. Indeed, we observed that CORM-3 pre-treatment ( $5 \mathrm{~min}$ ) or post-treatment (3 days) of rats after the onset of the hemorrhage elicited protective effects while administering the compound 3 hours after the stroke, in correspondence to the acute phase of the disease process, resulted in exacerbation of damage. The striking observation of this study is that one single dose of CORM-3 could modify the long-term inflammatory scenario that followed the hemorrhagic stroke by redirecting and limiting the infiltration of peripheral leukocytes and neutrophils in the brain and reducing the local activation of brain microglia and astrocytes induced by the stroke. Importantly, CORM-3 appeared to finely tune the levels of TNF- $\alpha$, by allowing its positive action in reparatory processes but inhibiting its detrimental effects. Thus, a growing body of literature supports a beneficial role of CO-RMs in inflammatory models but future investigations are required to better establish their therapeutic applications (see Figures 2 and 3 for the proposed mechanism of action of CO-RMs in vitro and in vivo).

\section{Mechanisms underlying the effects of CO-RMs on inflammation: modulation by oxidative stress}

It is well accepted that inflammatory stimuli promote a variety of responses that participate to exacerbate damage in cells and tissues but also promote the resolution of inflammation. Oxidative stress, derived from excessive and persistent production of reactive oxygen species (ROS) and a possible decrease in antioxidant defences, accompanies or precedes the increased amounts of inflammatory mediators upon inflammatory challenge. Because $\mathrm{CO}$ has a high affinity for different hemecontaining proteins - cytochromes in mitochondria and NADPH oxidase in the cell [77] - that contribute to regulate the levels of ROS, it is intriguing that part of the anti-inflammatory activities of CO-RMs may derive directly from inhibiting the generation of these damaging (or signalling) species. CO-RMs have shown a tendency to modulate pathways that produce ROS and the chemical nature of transition metal carbonyls might favour this reaction by allowing a selective transfer of CO from the CO-RMs to the target $[78,79]$. In RAW macrophages treated with LPS or PMA-stimulated neutrophils CORM-2 inhibited NADPH activity and overproduction of superoxide anion $\left(\mathrm{O}_{2}^{-}\right)$[80]. Similarly, CORM-A1 reduced the accumulation of ROS induced 


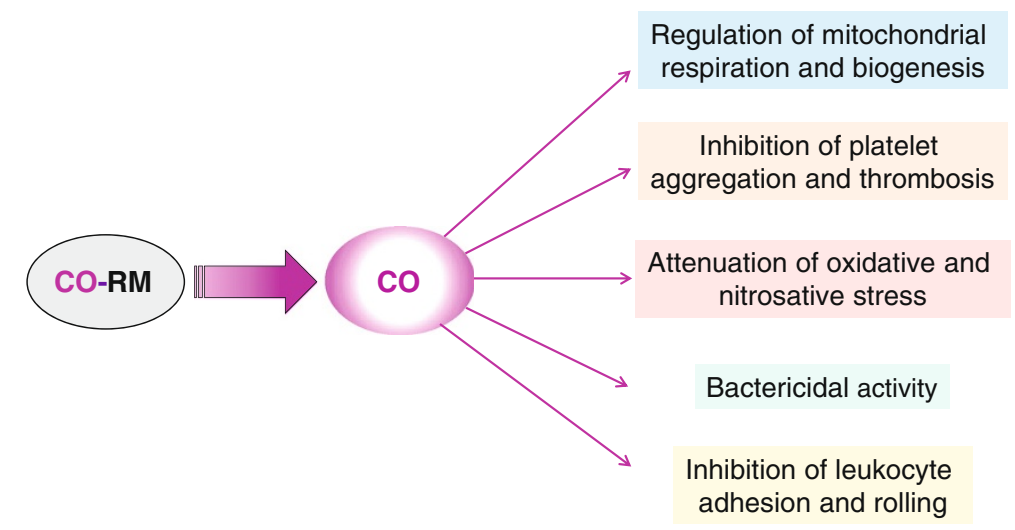

Figure 3 Schematic diagram representing the diverse effects of CO liberated from CO-RMs in vitro and in vivo (see text for details).

by TNF- $\alpha$ in pig cerebral microvascular endothelial cells, possibly by acting on a specific subunit of NADPH oxidase (Nox4) which is highly expressed in these cells $[40,81]$. Notably, a reduction in oxidative stress was reported also in chondrocytes from cartilage specimens of patients suffering from osteoarthritis, emphasizing both the relevance of these findings in primary human tissue and the idea that pathological processes occurring in diseased tissue can be modified by application of CO-RMs [51]. Oxidative stress levels were also significantly reduced by CORM-3 in intestinal tissue in a clinically relevant model of postoperative ileus and this was accompanied by partial restoration of antioxidant capacity levels [41]. Increased production of ROS following TNF- $\alpha /$ cycloheximide exposure was also diminished by CORM-A1 in a mouse intestinal epithelial cell line [82]. In summary, different CO-RMs can inhibit ROS/oxidative stress that results from inflammation, thus affecting an early and crucial mechanism that modulates subsequent inflammatory processes (see Figure 2).

\section{Mechanisms underlying the effects of CO-RMs on inflammation: modulation of inducible nitric oxide synthase (iNOS) and NO production}

Inflammation is a complex phenomenon; thus, it is anticipated that any anti-inflammatory properties of CO-RMs would involve a number of metabolic pathway. Overproduction of NO following up-regulation of inducible NO synthase (iNOS) is a critical step in the initiation and propagation of the inflammatory response [83] and diverse actions of CO-RMs in relation to this system have been described although with quite conflicting findings. We have observed that CORM-2 and CORM-3 decrease NO levels produced by macrophages stimulated with LPS without affecting iNOS protein expression [57] and because of these results we have postulated that $\mathrm{CO}$ from CO-RMs inhibited the activity of iNOS, a hemecontaining protein already shown in purified form to be blocked by $\mathrm{CO}$ gas [84]. Similar results were obtained in microglia by Min KJ et al. [85] while Megias and colleagues actually demonstrated that iNOS expression was reduced by CORM- 2 in Caco- 2 cells challenged with a combination of IL- $1 \beta$, TNF- $\alpha$ and IFN- $\gamma$ [52]. Other authors have reported the same observation in the gut [41] and in the spinal cord [23] following inflammatory damaging conditions, strengthening the idea that indeed CO-RMs exert an inhibitory effect on iNOS induction and activity. This would not perhaps be surprising if we consider that CO-RMs seem to affect the activation of $\mathrm{Nfk} \beta[24,25,52]$, which controls the expression iNOS and is a master regulator of major pathways in inflammation. However, until detailed studies designed to dissect the effect of CO-RMs on activity versus induction of iNOS are performed, it will not be clear whether CO-RMs can inhibit NO generation or iNOS expression. It may well be that inhibition of both can occur simultaneously or that one effect or the other will prevail depending on the inflammatory condition, tissue analyzed and the type of CO-RM investigated.

\section{Bactericidal activities of CO-RMs}

The threat of bacterial infection is omnipresent in surgical settings, wounds and contaminated food, any of which may lead to fatal consequences. Interestingly, CO-RMs have been shown to possess anti-bacterial properties that may be among the important therapeutic applications envisioned for this class of compounds. Lack of HMOX1 in mice resulted in an exaggerated lethality after cecal ligation and puncture (CLP), which caused polymicrobial sepsis [86]. However, the administration of CORM-2 was able to increase phagocytosis, decrease circulating bacterial counts, and rescue $\mathrm{HMOX1}^{-/-}$mice from the exaggerated mortality of CLP-induced sepsis, even when applied 6 hours after the initiation of infection. This is a remarkable result that 
emphasizes how these molecules can exert pleiotropic actions in such a complicated and severe pathological scenario. Desmard et al. also demonstrated that CORM-3, CORM-2 and, to a lesser extent, CORM-371, exert antibacterial actions against $P$. Aeruginosa in vitro and in vivo $[17,87]$. The ruthenium-based CO-RMs appeared more effective and CORM-A1 only exerted a transient bacteriostatic action, highlighting again the importance of the metal in mediating some activities of CO-RMs and perhaps guiding $\mathrm{CO}$ to the appropriate cellular target. More detailed work has been performed to investigate the direct effect of CO-RMs on different bacteria and the results have been reviewed elsewhere $[88,89]$.

Using more biochemical-oriented approaches, it has been possible to determine that terminal oxidases are targeted by CORM-3 when inhibiting bacterial growth $[17,44]$, thus impairing bacterial respiration. Moreover, oxidative stress caused by CO-RMs is another factor explaining some mechanistic actions of these compounds. According to Tavares et al., exposure of E. Coli to CORM-2 or a molybdenum-containing CO-RM increased the levels of intracellular ROS as well as causing DNA damage and disruption of Fe-S clusters [45]. The authors also showed that thiol-based antioxidants prevented the anti-microbial properties of CO-RMs, a finding we corroborated in studies using P. Aeruginosa $[17,87]$. However, in our work no effect of CORM-2 or CORM-3 on ROS production was detected as assessed by the use of a fluorescent probe [17], while in another collaborative investigation it was observed that thiols reduced the ROS production stimulated by CORM-2 in $P$. Aeruginosa biofilms but that this reduction was not accompanied by inhibition of bacterial growth [46]. Thus, the collective evidence suggests that CO-RMs interacts with metal-based proteins present in bacteria to exert various effects that are related to their bactericidal or bacteriostatic properties. However, it is possible that other pathways, susceptible to changes following application of CO-RMs, contribute to CO-RMs-mediated anti-microbial effects. In this regard, data obtained from microarray analysis of bacterial genes affected by exposing E. Coli to CORM-2 and CORM-3 have provided fascinating information about the pathways responding to CO-RMs $[44,90]$. It should be noted that one study looked at aerobically and anaerobically grown $E$ Coli and CORM-2 while the other investigated CORM-3 in anaerobically grown $E$ Coli, thus already indicating that different results should be expected from this analysis. Saraiva and colleagues have nicely summarized the diverse, and perhaps still incomplete, information collected in these two transcriptomic approaches showing that some pathways are typically changed in anaerobic conditions, some only in the aerobic state and some are instead commonly altered in E Coli grown either in aerobic or anaerobic conditions [88]. Of interest, genes involved in zinc homeostasis and the bacterial response to oxidative stress (SoxRS and OxyR) were increased in both conditions, perhaps stressing that, irrespective of the growth medium, the presence of ruthenium in CO-RMs and their propensity to cause oxidative stress/ inhibit the respiratory complexes will consistently occur. The fact that genes modulating biofilm pathways are affected is also a clear signal that E. Coli is suffering from exposure to CO-RMs and thus attempts to boost its resistance to these agents by promoting biofilm formation. In addition, increased methionine metabolism is triggered by CO-RMs, which may still be linked to an oxidative stress response.

In summary, few, but well designed and informative reports support the idea that CO-RMs are useful compounds to be employed alone or in combination with other antibiotics [46] to fight bacterial infection, taking into account the important notion that the bactericidal actions of CO-RM-s are elicited at concentrations that do not harm mammalian cells [17].

\section{Liberation of $\mathrm{CO}$ by CO-RMs: biochemical and pharmacological assays}

Assessing $\mathrm{CO}$ liberation from $\mathrm{CO}-\mathrm{RMs}$ has been a priority since our discovery of these compounds. Initially we developed a myoglobin assay for the detection of carbon monoxy myoglobin (MbCO) and employed an amperometric $\mathrm{CO}$ electrode to determine the rate and quantity of CO released [12,16]. Gas chromatography techiques have also been used by others to assess the spontaneous liberation of CO from CO-RMs in solution. In parallel, we used bioassays such as relaxation of aortic vessels and inhibition of the inflammatory response in macrophages to assess the CO-mediated pharmacological effects of CO-RMs $[12,57,91]$. In most cases we found a very good correlation between the rate and mode of $\mathrm{CO}$ release by CO-RMs and their effect on aortic ring relaxation. The results from several studies have also enabled us to propose that the chemical structure of metal carbonyls CO-RMs might facilitate the direct transfer of $\mathrm{CO}$ from CO-RMs to the intracellular target(s) as it appears that the release of $\mathrm{CO}$ from certain metal carbonyls (i.e. CORM-2 and CORM-3) requires an acceptor $[17,44,92]$. This may enhance selectivity for the action of $\mathrm{CO}$ from metal carbonyls and the difference with $\mathrm{CO}$ gas applied exogenously would be that its diffusion into cells might be limited or hampered by the encounter of many proteins potentially able to bind $\mathrm{CO}$, including the prototypic intracellular target(s) [17,77]. Although this concept needs to be substantiated, results on the bactericidal effects of CO-RMs (see above) and an interesting article published recently reports data in this direction. Wang and colleagues have developed a genetically 
encoded fluorescent probe, which is capable of selectively detecting $\mathrm{CO}$ inside living cell [93]. The probe, named COSer for $\mathrm{CO}$ sensor, consists of a permuted yellow fluorescent protein inserted into the regulatory domain of the bacterial protein CooA, a heme-dependent transcription factor known to bind $\mathrm{CO}$ with high affinity and selectivity. It was found that the fluorescent intensity of HeLa cells transfected with COSer increased after addition of $5 \mu \mathrm{M} \mathrm{CO}$ gas and a higher response was obtained with $10 \mu \mathrm{M}$. Interestingly, the fluorescence intensity was even stronger in cells treated with CORM-2 as a very significant response was obtained with only 1 $\mu \mathrm{M}$ CORM-2 and to obtain a given fluorescence intensity, more $\mathrm{CO}$ gas was needed with COSer-transfected cells than with the purified probe. These findings led the authors to state that CORM-2 provided an alternative and more controllable method for $\mathrm{CO}$ delivery to cells and could have possibly reduced the difficulty they encountered in getting $\mathrm{CO}$ into cells by using simple CO solutions. Similar findings were recently obtained by Michel and co-workers, who have synthesized a palladium-based fluorescent probe that is capable of detecting $\mathrm{CO}$ with high selectivity both in aqueous solutions and in living cells. Notably, CORM-3 was used in their experiments as the source of $\mathrm{CO}$ revealing that, unlike $\mathrm{CO}$ gas, concentrations as low as $1 \mu \mathrm{M}$ CORM-3 were sufficient to trigger fluorescence in cells loaded with the palladium probe [94].

The use of the $\mathrm{MbCO}$ assay to assess the rate and amount of $\mathrm{CO}$ liberated by CO-RMs has been recently questioned [95]. In our experiments we showed that while $\mathrm{MbCO}$ is promptly formed after addition of CORM-2 or CORM-3 to a solution containing reduced $\mathrm{Mb}$, a sensitive $\mathrm{CO}$ electrode failed to detect any $\mathrm{CO}$ upon addition of these two CO-RMs [17]. However, CO release from CORM-A1, a boranocarbonate, is detected by the $\mathrm{Mb}$ assay and by the electrode with comparable results, indicating the spontaneous liberation of $\mathrm{CO}$ from the compound. McLean and colleagues have shown that in the case of CORM-3 and CORM-2 liberation of $\mathrm{CO}$ and the consequent formation of $\mathrm{MbCO}$ is facilitated by dithionite, which is usually added in excess to the assay for keeping $\mathrm{Mb}$ in a reduced state [95]. The authors concluded that the $\mathrm{MbCO}$ assay should be abandoned and propose the use of hemoglobin $(\mathrm{Hb})$ since it binds $\mathrm{CO}$ with a much greater affinity than oxygen and does not require deoxygenation by dithionite. We believe these data indicate that dithionite and other sulphite can accelerate the release of CO from CO-RMs and that rates of $\mathrm{CO}$ release obtained with the $\mathrm{MbCO}$ assay should be interpreted cautiously, but we would like to add few important considerations still in favour of the $\mathrm{MbCO}$ assay. First, the results by McLean and colleagues seem to imply that liberation (or transfer) of $\mathrm{CO}$ from CORM-2 and CORM-3 to a prototypic target (i.e. $\mathrm{Mb}$ ) cannot occur in the presence of a deoxygenated reduced heme but is triggered only by interaction with anions such as sulphites. That this is not the case is elegantly described by Obirai and colleagues in an interesting report published few years ago revealing quite the opposite as CORM-2 was demonstrated to directly transfer $\mathrm{CO}$ to a heme(FeII)/heme(FeIII) redox couple [92]. Using a cyclic voltammetry method, the authors proved that when CORM-2 is added to an argon deaerated phosphate buffer solution containing an electrode coated with the heme redox couple but in complete absence of dithionite, a heme(FeII)-CO complex is formed. Secondly, the determination of the rate of CO liberation from CO-RMs by using an in vitro biochemical assay is rather approximate and we always judged it best to interpret our data on $\mathrm{CO}$ liberation using a combination of approaches as these compounds are designed for their possible therapeutic use in vivo. That is the reason why in our studies on the characterization of CO-RMs we always coupled the quantification of $\mathrm{CO}$ liberation in vitro with data obtained using bioassays that reflect more closely the behaviour of these compounds in complex biological systems. For instance, despite the fact that CORM-2 and CORM-3 are stable compounds in solution and may not liberate $\mathrm{CO}$ spontaneously, they still cause a rapid relaxation in isolated vessels and hypotension in animals suggesting that these compounds are fast $\mathrm{CO}$ releasers in vivo in line with the $\mathrm{MbCO}$ assay data. The bioactive effects mediated by the rapid $\mathrm{CO}$ release from these two CO-RMs have been corroborated by using pharmacological tools (i.e. inactive CO-RMs or CO-RMs depleted of CO) $[15,57,91]$ or by comparison with compounds that release $\mathrm{CO}$ much slower in vitro and in vivo (i.e. CORM-A1 and CORM-371) $[16,17]$. As a further example, we have recently employed the $\mathrm{MbCO}$ assay to determine that CORM-401, a manganese-containing $\mathrm{CO}-\mathrm{RM}$, liberates 3-4 $\mathrm{CO}$ per molecule [60]. We found that the relaxation exerted by this molecule in aortic rings is approximately 3 -fold more pronounced than that elicited by the same concentration of CORM-A1, which has a half-life similar to CORM-401 but liberates only 1 CO (unpublished results). Third, the use of oxygenated $\mathrm{Hb}$ instead of reduced $\mathrm{Mb}$ poses other relevant issues, such as the presence of 4 hemes and the co-operative effect of $\mathrm{CO}$ binding to the hemes, which will make it more difficult to quantify the amount and kinetics of $\mathrm{CO}$ released. These considerations, together with the results of the $\mathrm{MbCO}$ assay and the recent findings with the fluorescent probes reported above, strongly indicate that the release of CO from CORM-2 and CORM-3 occurs when the metal carbonyl is in the vicinity of a reduced iron acceptor $(\mathrm{MbFe}(\mathrm{II})$ or heme(II)). The results have also 
important implications on the efficacy of metal carbonyl $\mathrm{CO}-\mathrm{RMs}$ in delivering $\mathrm{CO}$ to prototypic intracellular targets.

\section{Conclusions}

Although the initial discovery of CO-RMs took place a decade ago [12], it is intriguing that many diverse and novel pharmacological actions are being discovered for these compounds. The studies conducted so far reflect a real effort to understand the biochemical mechanisms that mediate the beneficial effects of CO-RMs. The emerging scenario is that, while CO-RMs mainly affect cellular functions via the liberation of $\mathrm{CO}$, the molecules may facilitate or modulate other concomitant reactions involving redox and metal-sensitive pathways. Importantly, the chemical reactivity of metal carbonyl complexes-based CO-RMs may be enriching, rather than diminishing, their positive actions suggesting that a critical assessment of CO-RMs' behaviour in biological environment (bioassays) must always be evaluated in parallel to their ability to release $\mathrm{CO}$. In view of the growing importance of inflammatory components in initiating and modulating pathological processes, we have focused here on how CO-RMs modulate the inflammatory response as consistent and converging data point to their interesting anti-inflammatory activity. As new CORMs with a multiplicity of chemical properties and reactivity are being synthesized and tested in biological models, we may in the future uncover novel promising applications for this unique class of compounds.

\begin{abstract}
Abbreviations
CLP: Cecal ligation and puncture; CO: Carbon monoxide; CO-RMs: Carbon monoxide-releasing molecules; $\mathrm{CO}$ : Carbon monoxide; $\mathrm{CORM}-2$ : $\left[\mathrm{Ru}(\mathrm{CO})_{3} \mathrm{Cl} \mathrm{C}_{2}\right)$ also known as tricarbonyldichlororuthenium(II) dimer;

CORM-3: Ru(CO)3Cl(glycinate) also known as tricarbonylchloro(glycinato) ruthenium(II); CORM-371: $\left[\mathrm{Me}_{4} \mathrm{~N}\right]\left[\mathrm{Mn}(\mathrm{CO})_{4}(\text { thioacetate) })_{2}\right]$; CORM-A1: $\mathrm{NaH}_{3} \mathrm{BCOOH}$, also known as sodium boranocarbonates; COX-2: Cyclooxygenase-2; Hb: Hemoglobin; (HMOX1): Heme oxygenase-1; ICAM-1: Intercellular adhesion molecule 1; IL: Interleukin; IL-1ß: Interleukin 1 beta; iNOS: Inducible nitric oxide synthase or NOS(III); LPS: Lypopolysaccharide; MAPKS: Mitogen activated protein kinases; Mb: Myoglobin; MbCO: Carbon monoxy myoglobin; MMP: Matrix metallo proteinase; MPO: Myeloperoxidase; NO: Nitric oxide; $\mathrm{Nfk} \beta$ : Nuclear factor kappa beta; $\mathrm{O}_{2}^{-}$: Superoxide anion; PGE2: Prostaglandin E2; PMNs: Polymorphonuclear neutrophils; ROS: Reactive oxygen species; TNF-a: Tumor necrosis factor alpha.
\end{abstract}

\section{Competing interests}

Dr. Roberto Motterlini was founder and scientific director of hemoCORM (2004-2008), holds patents on the CO-RMs technology and is a shareholder of Alfama.

\section{Authors' contribution}

RM and RF wrote the manuscript. BH drafted an earlier version of the manuscript and helped with the outline of Table 1. All authors have read and approved the manuscript.

\section{Acknowledgements}

We would like to thank the AREMCAR Foundation for financial support. The authors would also like to thank Prof. Brian Mann (University of Sheffield, United Kingdom) and all the former colleagues at Northwick Park Institute for Medical Research (Harrow, United Kingdom) for their contribution and support.

Received: 4 October 2012 Accepted: 7 November 2012 Published: 21 November 2012

\section{References}

1. Tenhunen R, Marver HS, Schmid R: Microsomal heme oxygenase. Characterization of the enzyme. J Biol Chem 1969, 244:6388-6394.

2. Maines MD: Heme oxygenase: function, multiplicity, regulatory mechanisms, and clinical applications. FASEB J 1988, 2:2557-2568.

3. Ingi T, Chiang G, Ronnett GV: The regulation of heme turnover and carbon monoxide biosynthesis in cultured primary rat olfactory receptor neurons. J Neurosci 1996, 16:5621-5628.

4. Motterlini R, Gonzales A, Foresti R, Clark JE, Green CJ, Winslow RM: Heme oxygenase-1-derived carbon monoxide contributes to the suppression of acute hypertensive responses in vivo. Circ Res 1998, 83:568-577.

5. Applegate LA, Luscher P, Tyrrell RM: Induction of heme oxygenase: a general response to oxidant stress in cultured mammalian cells. Cancer Res 1991, 51:974-978.

6. Ewing JF, Maines MD: Rapid induction of heme oxygenase-1 mRNA and protein by hyperthermia in rat brain: heme oxygenase- 2 is not a heat shock protein. Proc Natl Acad Sci USA 1991, 88:5364-5368.

7. Stocker R, Yamamoto Y, McDonagh AF, Glazer AN, Ames BN: Bilirubin is an antioxidant of possible physiological importance. Science 1987, 235:1043-1046.

8. Otterbein LE, Bach FH, Alam J, Soares M, Tao Lu H, Wysk M, Davis RJ, Flavell RA, Choi AM: Carbon monoxide has anti-inflammatory effects involving the mitogen-activated protein kinase pathway. Nature Med 2000, 6:422-428.

9. Motterlini R, Otterbein LE: The therapeutic potential of carbon monoxide. Nat Rev Drug Discov 2010, 9:728-743.

10. Ryter SW, Otterbein LE: Carbon monoxide in biology and medicine. BioEssays 2004, 26:270-280.

11. Otterbein LE: Carbon monoxide: innovative anti-inflammatory properties of an age-old gas molecule. Antioxid Redox Signal 2002, 4:309-319.

12. Motterlini R, Clark JE, Foresti R, Sarathchandra P, Mann BE, Green CJ: Carbon monoxide-releasing molecules: characterization of biochemical and vascular activities. Circ Res 2002, 90:E17-E24.

13. Johnson TR, Mann BE, Clark JE, Foresti R, Green CJ, Motterlini R: Metal carbonyls: a new class of pharmaceuticals? Angew Chem Int Ed Engl 2003, 42:3722-3729

14. Motterlini R, Mann BE, Johnson TR, Clark JE, Foresti R, Green CJ: Bioactivity and pharmacological actions of carbon monoxide-releasing molecules. Curr Pharmacol Design 2003, 9:2525-2539.

15. Clark JE, Naughton P, Shurey S, Green CJ, Johnson TR, Mann BE, Foresti R, Motterlini R: Cardioprotective actions by a water-soluble carbon monoxide-releasing molecule. Circ Res 2003, 93:e2-e8.

16. Motterlini R, Sawle P, Bains S, Hammad J, Alberto R, Foresti R, Green CJ: CORM-A1: a new pharmacologically active carbon monoxide-releasing molecule. FASEB J 2005, 19:284-286.

17. Desmard M, Foresti R, Morin D, Dagoussat M, Berdeaux A, Denamur E, Crook SH, Mann BE, Scapens D, Montravers P, Boczkowski J, Motterlini R: Differential antibacterial activity against pseudomonas aeruginosa by carbon monoxide-releasing molecules. Antioxid Redox Signal 2011, 16:153-163.

18. Kramkowski K, Leszczynska A, Mogielnicki A, Chlopicki S, Fedorowicz A, Grochal E, Mann B, Brzoska T, Urano T, Motterlini R, Buczko W: Antithrombotic properties of water-soluble carbon monoxide-releasing molecules. Arterioscler Thromb Vasc Biol 2012, 32:2149-2157.

19. Yabluchanskiy A, Sawle P, Homer-Vanniasinkam S, Green CJ, Foresti R, Motterlini R: CORM-3, a carbon monoxide-releasing molecule, alters the inflammatory response and reduces brain damage in a rat model of hemorrhagic stroke. Crit Care Med 2012, 40:544-552.

20. Fei D, Meng X, Zhao M, Kang K, Tan G, Pan S, Luo Y, Liu W, Nan C, Jiang H, Krissansen GW, Zhao M, Sun X: Enhanced induction of heme oxygenase-1 suppresses thrombus formation and affects the protein $\mathrm{C}$ system in sepsis. Transl Res 2012, 159:99-109.

21. Ibanez L, Alcaraz MJ, Maicas N, Guede D, Caeiro JR, Motterlini R, Ferrandiz ML: Downregulation of the inflammatory response by CORM-3 results in 
protective effects in a model of postmenopausal arthritis. Calcif Tissue Int 2012, 91:69-80.

22. Maruyama K, Morishita E, Yuno T, Sekiya A, Asakura H, Ohtake S, Yachie A: Carbon monoxide (CO)-releasing molecule-derived $\mathrm{CO}$ regulates tissue factor and plasminogen activator inhibitor type 1 in human endothelial cells. Thromb Res 2012, 130:e188-e193.

23. Hervera A, Leanez S, Negrete R, Motterlini R, Pol O: Carbon monoxide reduces neuropathic pain and spinal microglial activation by inhibiting nitric oxide synthesis in mice. PLOS One 2012, 7:e43693.

24. Song H, Bergstrasser C, Rafat N, Hoger S, Schmidt M, Endres N, Goebeler M, Hillebrands JL, Brigelius-Flohe R, Banning A, Beck G, Loesel R, Yard BA: The carbon monoxide releasing molecule (CORM-3) inhibits expression of vascular cell adhesion molecule-1 and E-selectin independently of haem oxygenase-1 expression. Br J Pharmacol 2009, 157:769-780.

25. Sun B, Zou X, Chen Y, Zhang P, Shi G: Preconditioning of carbon monoxide releasing molecule-derived $C O$ attenuates LPS-induced activation of HUVEC. Int J Biol Sci 2008, 4:270-278.

26. Bergstraesser $C$, Hoeger $S$, Song H, Ermantraut L, Hottenrot M, Czymai T, Schmidt M, Goebeler M, Ponelies N, Stich C, Loesel R, Molema G, Seelen M, van Son W, Yard BA, Rafat N: Inhibition of VCAM-1 expression in endothelial cells by CORM-3: the role of the ubiquitin-proteasome system, p38, and mitochondrial respiration. Free Radic Biol Med 2012, 52:794-802.

27. Caumartin Y, Stephen J, Deng JP, Lian D, Lan Z, Liu W, Garcia B, Jevnikar AM, Wang H, Cepinskas G, Luke PP: Carbon monoxide-releasing molecules protect against ischemia-reperfusion injury during kidney transplantation. Kidney Int 2011, 79:1080-1089.

28. Takagi T, Naito Y, Uchiyama K, Suzuki T, Hirata I, Mizushima K, Tsuboi H, Hayashi N, Handa O, Ishikawa T, Yagi N, Kokura S, Ichikawa H, Yoshikawa T: Carbon monoxide liberated from carbon monoxide-releasing molecule exerts an anti-inflammatory effect on dextran sulfate sodium-induced colitis in mice. Dig Dis Sci 2011, 56:1663-1671.

29. Chung J, Shin DY, Zheng M, Joe Y, Pae HO, Ryter SW, Chung HT: Carbon monoxide, a reaction product of heme oxygenase-1, suppresses the expression of C-reactive protein by endoplasmic reticulum stress through modulation of the unfolded protein response. Mol Immunol 2011, 48:1793-1799.

30. Ahanger AA, Prawez S, Kumar D, Prasad R, Amarpal, Tandan SK, Kumar D Wound healing activity of carbon monoxide liberated from CO-releasing molecule (CO-RM). Naunyn Schmiedebergs Arch Pharmacol 2011, 384:93-102

31. Wei Y, Chen P, de Bruyn M, Zhang W, Bremer E, Helfrich W: Carbon monoxide-releasing molecule-2 (CORM-2) attenuates acute hepatic ischemia reperfusion injury in rats. BMC Gastroenterol 2010, 10:42.

32. Chen P, Sun B, Chen H, Wang G, Pan S, Kong R, Bai X, Wang S: Effects of carbon monoxide releasing molecule-liberated $\mathrm{CO}$ on severe acute pancreatitis in rats. Cytokine 2010, 49:15-23.

33. Maicas N, Ferrandiz ML, Devesa I, Motterlini R, Koenders MI, van den Berg WB, Alcaraz MJ: The CO-releasing molecule CORM-3 protects against articular degradation in the $\mathrm{K} / \mathrm{BxN}$ serum transfer arthritis model. Eur J Pharmacol 2010, 634:184-191.

34. Katada K, Bihari A, Mizuguchi S, Yoshida N, Yoshikawa T, Fraser DD, Potter RF, Cepinskas G: Carbon monoxide liberated from CO-releasing molecule (CORM-2) attenuates ischemia/reperfusion (I/R)-induced inflammation in the small intestine. Inflammation 2010, 33:92-100.

35. Lin LC, Ho FM, Yen SJ, Wu PY, Hung LF, Huang WJ, Liang YC: Carbon monoxide induces cyclooxygenase-2 expression through MAPKs and PKG in phagocytes. Int Immunopharmacol 2010, 10:1520-1525.

36. Lancel S, Hassoun SM, Favory R, Decoster B, Motterlini R, Neviere R: Carbon monoxide rescues mice from lethal sepsis by supporting mitochondrial energetic metabolism and activating mitochondrial biogenesis. J Pharmacol Exp Ther 2009, 1329:641-648.

37. Mizuguchi S, Stephen J, Dencev-Bihari R, Markovic N, Suehiro S, Capretta F, Potter RF, Cepinskas G: CO-releasing molecule (CORM-3)-derived CO modulates neutrophil (PMN) migration across vascular endothelium by reducing the levels of cell surface-bound elastase. Am J Physiol Heart Circ Physiol 2009, 297:H920-H929.

38. Tsoyi K, Lee TY, Lee YS, Kim HJ, Seo HG, Lee JH, Chang KC: Heme-oxygenase-1 induction and carbon monoxide-releasing molecule inhibit lipopolysaccharide (LPS)-induced high-mobility group box 1 release in vitro and improve survival of mice in LPS- and cecal ligation and puncture-induced sepsis model in vivo. Mol Pharmacol 2009, 76:173-182.

39. Cepinskas G, Katada K, Bihari A, Potter RF: Carbon monoxide liberated from carbon monoxide-releasing molecule CORM-2 attenuates inflammation in the liver of septic mice. Am J Physiol Gastrointest Liver Physiol 2008, 294:G184-G191.

40. Basuroy S, Bhattacharya S, Leffler CW, Parfenova H: Nox4 NADPH oxidase mediates oxidative stress and apoptosis caused by TNF-a in cerebral vascular endothelial cells. Am J Physiol Cell Physiol 2009, 296:C422-C432

41. De Backer O, Elinck E, Blanckaert B, Leybaert L, Motterlini R, Lefebvre RA: Water-soluble CO-releasing molecules (CO-RMs) reduce the development of postoperative ileus via modulation of MAPK/HO-1 signaling and reduction of oxidative stress. Gut 2009, 58:347-356.

42. Sun BW, Sun $Y$, Sun ZW, Chen X: CO liberated from CORM-2 modulates the inflammatory response in the liver of thermally injured mice. World $J$ Gastroenterol 2008, 14:547-553.

43. Sun BW, Jin Q, Sun Y, Sun ZW, Chen X, Chen ZY, Cepinskas G: Carbon liberated from CO-releasing molecules attenuates leukocyte infiltration in the small intestine of thermally injured mice. World J Gastroenterol 2007, 13:6183-6190.

44. Davidge KS, Sanguinetti G, Yee CH, Cox AG, McLeod CW, Monk CE, Mann BE, Motterlini R, Poole RK: Carbon monoxide-releasing antibacterial molecules target respiration and global transcriptional regulators. J Biol Chem 2009, 284:4516-4524.

45. Tavares AF, Teixeira M, Romao CC, Seixas JD, Nobre LS, Saraiva LM: Reactive oxygen species mediate bactericidal killing elicited by carbon monoxidereleasing molecules. J Biol Chem 2011, 286:26708-26717.

46. Murray TS, Okegbe C, Gao Y, Kazmierczak BI, Motterlini R, Dietrich LE, Bruscia EM: The carbon monoxide releasing molecule CORM-2 attenuates Pseudomonas aeruginosa biofilm formation. PLoS One 2012, 7:e35499.

47. Nobre LS, Seixas JD, Romao CC, Saraiva LM: Antimicrobial action of carbon monoxide-releasing compounds. Antimicrob Agents Chemother 2007, 51:4303-4307

48. Takamiya R, Hung CC, Hall SR, Fukunaga K, Nagaishi T, Maeno T, Owen C, Macias AA, Fredenburgh LE, Ishizaka A, Blumberg RS, Baron RM, Perrella MA: High mobility group Box 1 contributes to lethality of endotoxemia in heme oxygenase-1 deficient mice. Am J Respir Cell Mol Biol 2008, 41:129-135.

49. Ferrandiz ML, Maicas N, Garcia-Arnandis I, Terencio MC, Motterlini R, Devesa I, Joosten LA, van den Berg WB, Alcaraz MJ: Treatment with a CO-releasing molecule (CORM-3) reduces joint inflammation and erosion in murine collagen-induced arthritis. Ann Rheum Dis 2008, 67:1211-1217.

50. Masini E, Vannacci A, Failli P, Mastroianni R, Giannini L, Vinci MC, Uliva C, Motterlini R, Mannaioni PF: A carbon monoxide-releasing molecule (CORM-3) abrogates polymorphonuclear granulocyte-induced activation of endothelial cells and mast cells. FASEB J 2008, 22:3380-3388.

51. Guillen MI, Megias J, Clerigues V, Gomar F, Alcaraz MJ: The CO-releasing molecule CORM-2 is a novel regulator of the inflammatory process in osteoarthritic chondrocytes. Rheumatology (Oxford) 2008, 47:1323-1328.

52. Megias J, Busserolles J, Alcaraz MJ: The carbon monoxide-releasing molecule CORM-2 inhibits the inflammatory response induced by cytokines in Caco-2 cells. Br J Pharmacol 2007, 150:977-986.

53. Megias J, Guillen MI, Bru A, Gomar F, Alcaraz MJ: The carbon monoxidereleasing molecule tricarbonyldichlororuthenium(II) dimer protects human osteoarthritic chondrocytes and cartilage from the catabolic actions of interleukin-1beta. J Pharmacol Exp Ther 2008, 325:56-61.

54. Urquhart $P$, Rosignoli G, Cooper D, Motterlini R, Perretti M: Carbon monoxide-releasing molecules modulate leukocyte-endothelial interactions under flow. J Pharmacol Exp Ther 2007, 321:656-662.

55. Bani-Hani MG, Greenstein D, Mann BE, Green CJ, Motterlini R: Modulation of thrombin-induced neuroinflammation in BV-2 microglia by a carbon monoxide-releasing molecule (CORM-3). J Pharmacol Exp Ther 2006, 318:1315-1322.

56. Bani-Hani MG, Greenstein D, Mann BE, Green CJ, Motterlini R: A carbon monoxide-releasing molecule (CORM-3) attenuates lipopolysaccharideand interferon-gamma-induced inflammation in microglia. Pharmacol Rep 2006, 58(Suppl):132-144.

57. Sawle P, Foresti R, Mann BE, Johnson TR, Green CJ, Motterlini R: Carbon monoxide-releasing molecules (CO-RMs) attenuate the inflammatory response elicited by lipopolysaccharide in RAW264.7 murine macrophages. Br J Pharmacol 2005, 145:800-810. 
58. Sawle P, Hammad J, Fairlamb IJ, Moulton B, O'Brien CT, Lynam JM, Duhme-Klair AK, Foresti R, Motterlini R: Bioactive properties of iron-containing carbon monoxide-releasing molecules (CO-RMs). J Pharmacol Exp Ther 2006, 318:403-410.

59. Hewison L, Crook SH, Johnson TR, Mann BE, Adams H, Plant SE, Sawle P, Motterlini R: Iron indenyl carbonyl compounds: CO-releasing molecules. Dalton Trans 2010, 39:8967-8975.

60. Crook SH, Mann BE, Meijer JAHM, Adams H, Sawle P, Scapens D, Motterlini R: $\left[\mathrm{Mn}(\mathrm{CO})_{4}\left\{\mathrm{~S}_{2} \mathrm{CNMe}\left(\mathrm{CH}_{2} \mathrm{CO}_{2} \mathrm{H}\right)\right\}\right]$, a new water-soluble CO-releasing molecule. Dalton Trans 2011, 40:4230-4235.

61. Szabo C: Gaseotransmitters: new frontiers for translational science. SCi Transl Med 2010, 2:59ps54.

62. Oresmaa L, Tarvainen H, Machal K, Haukka M: Ruthenium imidazole oxime carbonyls and their activities as CO-releasing molecules. Dalton Trans 2012, 41:11170-11175.

63. Schatzschneider U: Photoactivated biological activity of transition-metal complexes. Eur J Inorg Chem 2010, 41:1451-1467.

64. Dordelmann G, Pfeiffer H, Birkner A, Schatzschneider U: Silicium dioxide nanoparticles as carriers for photoactivatable CO-releasing molecules (PhotoCORMs). Inorg Chem 2011, 50:4362-4367.

65. Romanski S, Kraus B, Schatzschneider U, Neudorfl JM, Amslinger S, Schmalz HG: Acyloxybutadiene iron tricarbonyl complexes as enzyme-triggered CO-releasing molecules (ET-CORMs). Angew Chem Int Ed Engl 2011 50:2392-2396.

66. Hasegawa U, van der Vlies AJ, Simeoni E, Wandrey C, Hubbell JA: Carbon monoxide-releasing micelles for immunotherapy. J Am Chem Soc 2010, 132:18273-18280.

67. Zobi F, Degonda A, Schaub MC, Bogdanova AY: CO releasing properties and cytoprotective effect of cis-trans-[Re(II)(CO) $\left.{ }_{2} \mathrm{Br}_{2} \mathrm{~L}_{2}\right]$ n complexes. Inorg Chem 2010, 49:7313-7322.

68. Koenitzer JR, Freeman BA: Redox signaling in inflammation: interactions of endogenous electrophiles and mitochondria in cardiovascular disease. Ann N Y Acad Sci 2010, 1203:45-52.

69. Willis D, Moore AR, Frederick R, Willoughby DA: Heme oxygenase: a novel target for the modulation of inflammatory response. Nature Med 1996, 2:87-90.

70. Yachie A, Niida Y, Wada T, Igarashi N, Kaneda H, Toma T, Ohta K, Kasahara Y, Koizumi S: Oxidative stress causes enhanced endothelial cell injury in human heme oxygenase-1 deficiency. J Clin Invest 1999, 103:129-135.

71. Poss KD, Tonegawa S: Heme oxygenase 1 is required for mammalian iron reutilization. Proc Natl Acad Sci USA 1997, 94:10919-10924.

72. Bellner L, Wolstein J, Patil KA, Dunn MW, Laniado-Schwartzman M: Biliverdin rescues the $\mathrm{HO}-2$ null mouse phenotype of unresolved chronic inflammation following corneal epithelial injury. Invest Ophthalmol Vis Sci 2011, 52:3246-3253

73. Sarady-Andrews JK, Liu F, Gallo D, Nakao A, Overhaus M, Ollinger R, Choi AM, Otterbein LE: Biliverdin administration protects against endotoxininduced acute lung injury in rats. Am J Physiol Lung Cell Mol Physiol 2005, 289:L1131-L1137.

74. Ryter SW, Alam J, Choi AM: Heme oxygenase-1/carbon monoxide: from basic science to therapeutic applications. Physiol Rev 2006, 86:583-650.

75. Sun B, Sun H, Liu C, Shen J, Chen Z, Chen X: Role of CO-releasing molecules liberated $\mathrm{CO}$ in attenuating leukocytes sequestration and inflammatory responses in the lung of thermally injured mice. J Surg Res 2007, 139:128-135.

76. Lancel S, Montaigne D, Marechal X, Marciniak C, Hassoun SM, Decoster B, Ballot C, Blazejewski C, Corseaux D, Lescure B, Motterlini R, Neviere R: Carbon monoxide improves cardiac function and mitochondrial population quality in a mouse model of metabolic syndrome. PLOS One 2012, 7:e41836.

77. Foresti $R$, Motterlini $R$ : Interaction of carbon monoxide with transition metals: evolutionary insights into drug target discovery. Curr Drug Targets 2010, 11:1595-1604.

78. Taille C, El-Benna J, Lanone S, Boczkowski J, Motterlini R: Mitochondrial respiratory chain and $\mathrm{NAD}(\mathrm{P}) \mathrm{H}$ oxidase are targets for the antiproliferative effect of carbon monoxide in human airway smooth muscle. J Biol Chem 2005, 280:25350-25360.

79. Lo lacono L, Boczkowski J, Zini R, Salouage I, Berdeaux A, Motterlini R, Morin D: A carbon monoxide-releasing molecule (CORM-3) uncouples mitochondrial respiration and modulates the production of reactive oxygen species. Free Rad Biol Med 2011, 50:1556-1564.
80. Srisook K, Han SS, Choi HS, Li MH, Ueda H, Kim C, Cha YN: CO from enhanced $\mathrm{HO}$ activity or from CORM-2 inhibits both O2- and NO production and downregulates HO-1 expression in LPS-stimulated macrophages. Biochem Pharmacol 2006, 71:307-318.

81. Basuroy S, Bhattacharya S, Tcheranova D, Qu Y, Regan RF, Leffler CW, Parfenova H: Heme Oxygenase-2 provides endogenous protection against oxidative stress and apoptosis caused by TNF- $a$ in cerebral vascular endothelial cells. Am J Physiol Cell Physiol 2006, 291:C897-C908.

82. Babu D, Soenen SJ, Raemdonck K, Leclercq G, De Backer O, Motterlini R, Lefebvre RA: TNF-alpha/cycloheximide-induced oxidative stress and apoptosis in murine intestinal epithelial MODE-K cells. Curr Pharm Des 2012, 18:4414-4425.

83. Hierholzer C, Harbrecht B, Menezes JM, Kane J, MacMicking J, Nathan CF, Peitzman AB, Billiar TR, Tweardy DJ: Essential role of induced nitric oxide in the initiation of the inflammatory response after hemorrhagic shock. J Exp Med 1998, 187:917-928.

84. AbuSoud HM, Wu CQ, Ghosh DK, Stuehr DJ: Stopped-flow analysis of CO and NO binding to inducible nitric oxide synthase. Biochemistry 1998, 37:3777-3786.

85. Min KJ, Yang MS, Kim SU, Jou I, Joe EH: Astrocytes induce hemeoxygenase- 1 expression in microglia: a feasible mechanism for preventing excessive brain inflammation. J Neurosci 2006, 26:1880-1887.

86. Chung SW, Liu X, Macias AA, Baron RM, Perrella MA: Heme oxygenase-1derived carbon monoxide enhances the host defense response to microbial sepsis in mice. J Clin Invest 2008, 118:239-247.

87. Desmard M, Davidge KS, Bouvet O, Morin D, Roux D, Foresti R, Ricard JD, Denamur E, Poole RK, Montravers P, Motterlini R, Boczkowski J: A carbon monoxide-releasing molecule (CORM-3) exerts bactericidal activity against Pseudomonas aeruginosa and improves survival in an animal model of bacteraemia. FASEB J 2009, 23:1023-1031.

88. Tavares AF, Nobre LS, Saraiva LM: A role for reactive oxygen species in the antibacterial properties of carbon monoxide-releasing molecules. FEMS Microbiol Lett 2012, 336:1-10.

89. Wilson $\mathrm{J}$, Jesse HE, Poole RK, Davidge KS: Antibacterial effects of carbon monoxide. Curr Pharm Biotechnol 2012, 13:760-768.

90. Nobre LS, Al Shahrour F, Dopazo J, Saraiva LM: Exploring the antimicrobial action of a carbon monoxide-releasing compound through wholegenome transcription profiling of Escherichia coli. Microbiology 2009, 155:813-824.

91. Foresti R, Hammad J, Clark JE, Johnson RA, Mann BE, Friebe A, Green CJ, Motterlini R: Vasoactive properties of CORM-3, a novel water-soluble carbon monoxide-releasing molecule. Br J Pharmacol 2004, 142:453-460.

92. Obirai JC, Hamadi S, Ithurbide A, Wartelle C, Nyokong T, Zagal J, Top S, Bedioui F: UV-visible and electrochemical monitoring of carbon monoxide release by donor complexes to myoglobin solutions and to electrodes modified with films containing hemin. Electroanalyis 2006, 18:1689-1695.

93. Wang J, Karpus J, Zhao BS, Luo Z, Chen PR, He C: A selective fluorescent probe for carbon monoxide imaging in living cells. Angew Chem Int Ed Engl 2012, 51:9652-9656.

94. Michel BW, Lippert AR, Chang CJ: A reaction-based fluorescent probe for selective imaging of carbon monoxide in living cells using a palladiummediated carbonylation. J Am Chem Soc 2012, 134:15668-15671.

95. McLean S, Mann BE, Poole RK: Sulfite species enhance carbon monoxide release from CO-releasing molecules: implications for the deoxymyoglobin assay of activity. Anal Biochem 2012, 427:36-40.

doi:10.1186/2045-9912-2-28

Cite this article as: Motterlini et al:: Emerging concepts on the antiinflammatory actions of carbon monoxide-releasing molecules (CORMs). Medical Gas Research 2012 2:28. 